\title{
Rural Emergency Nurses' Suggestions for Improving End-of-Life Care
}

Renea L. Beckstrand

Brigham Young University - Provo

Kelly E. Smith

Brigham Young University - Provo

Karlen E. (Bethy) Luthy

Brigham Young University - Provo

Janelle L. B. Macintosh

Brigham Young University - Provo, janelle-macintosh@byu.edu

Follow this and additional works at: https://scholarsarchive.byu.edu/facpub

Part of the Critical Care Nursing Commons, and the Other Nursing Commons

\section{Original Publication Citation}

Beckstrand, R. L., Smith, K. E.**, Luthy, K. E. B., \& Macintosh, J. L. (2017). Rural emergency nurses' suggestions for improving end-of-life care. Journal of Emergency Nursing, 43(3), 214-220.

\section{BYU ScholarsArchive Citation}

Beckstrand, Renea L.; Smith, Kelly E.; Luthy, Karlen E. (Bethy); and Macintosh, Janelle L. B., "Rural Emergency Nurses' Suggestions for Improving End-of-Life Care" (2017). Faculty Publications. 5202. https://scholarsarchive.byu.edu/facpub/5202 accepted for inclusion in Faculty Publications by an authorized administrator of BYU ScholarsArchive. For more information, please contact ellen_amatangelo@byu.edu. 


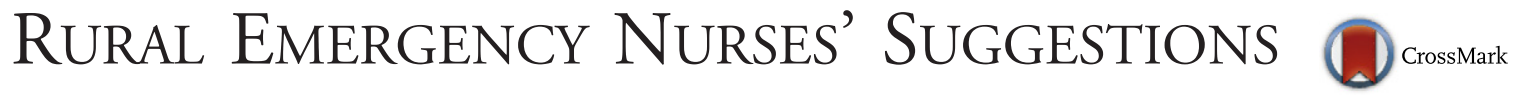 FOR IMPROVING END-OF-LIFE CARE
}

\author{
Authors: Renea L. Beckstrand, PhD, RN, CCRN, CNE, Kelly E. Smith, MS, FNP, Karlen E. (Beth) Luthy, DNP, FNP, FAAN, and \\ Janelle L.B. Macintosh, PhD, RN, Provo, UT
}

\begin{abstract}
Introduction: Many patient visits to emergency departments result in the patient dying or being pronounced dead on arrival. The numbers of deaths in emergency departments are likely to increase as a significant portion of the U.S. population ages. Consequently, emergency nurses face many obstacles to providing quality end-of-life (EOL) care when death occurs. The purpose of this study was to identify suggestions that emergency nurses have to improve EOL care, specifically in rural emergency departments.
\end{abstract}

Methods: A 57-item questionnaire was sent to 53 rural hospitals in 4 states in the Intermountain West, plus Alaska. One item asked nurses to identify the one aspect of EOL care they would change for dying patients in rural emergency departments. Each qualitative response was individually reviewed by a research team and then coded into a theme.

Results: Four major themes and three minor themes were identified. The major themes were providing greater privacy during EOL care for patients and family members, increasing availability of support services, additional staffing, and improved staff and community education.

Discussion: Providing adequate privacy for patients and family members was a major obstacle to providing EOL care in the emergency department, largely because of poor department design, especially in rural emergency departments where space is limited. Lack of support services and adequate staffing were also obstacles to providing quality EOL care in rural emergency departments. Consequently, rural nurses are commonly pulled away from EOL care to perform ancillary duties because additional support personnel are lacking. Providing EOL care in rural emergency departments is a challenging task given the limited staffing and resources, and thus it is imperative that nurses' suggestions for improvement of EOL care be acknowledged. Because of the current lack of research in rural EOL care, additional research is needed.

Key words: End-of-life care; Rural; Emergency department; Emergency nurses; Obstacles; Suggestions
$\mathrm{D}$ eath is a part of life that can be neither avoided nor predicted. In 2010, of the 129 million visits to the emergency department, 240,000 resulted in the patient dying or being pronounced dead on arrival. ${ }^{1}$ Although care in the emergency department is focused on saving lives and returning patients to a healthy state, death cannot always be prevented. ${ }^{2}$

Renea L. Beckstrand is Professor, College of Nursing, Brigham Young University, Provo, UT.

Kelly E. Smith is FNP Student, College of Nursing, Brigham Young University, Provo, UT.

Karlen E. (Beth) Luthy is Assistant Professor, College of Nursing, Brigham Young University, Provo, UT.

Janelle L. B. Macintosh is Assistant Professor, College of Nursing, Brigham Young University, Provo, UT.

For correspondence, write: Renea L. Beckstrand, PhD, RN, CCRN, CNE, College of Nursing, Brigham Young University, 422 SWKT, PO Box 25432, Provo, UT 84602-5432; E-mail: renea@byu.edu.

J Emerg Nurs 2015;43:214-20.

0099-1767

Copyright (@) 2015 Emergency Nurses Association. Published by Elsevier Inc. All rights reserved.

http://dx.doi.org/10.1016/j.jen.2017.03.012
As the population of the United States continues to age, ED visits of the aging population also continue to rise. ${ }^{1}$ It is estimated that 1 in 5 persons will be age 65 years and older by the year $2030 .{ }^{3}$ Consequently, the number of patients who are at the end of life (EOL) or dying will increase, further taxing the already limited resources available to provide EOL care in the emergency department. Thus it is imperative that both obstacles and helpful or supportive behaviors to providing EOL care in the emergency department be identified.

Providing care to dying patients, regardless of their age, is a responsibility that all emergency nurses assume at some point in their careers. However, because emergency nurses are primarily trained to save lives, they often encounter obstacles to providing EOL care to dying patients, especially in rural settings where staffing and resources are limited. ${ }^{2}$

\section{Background}

From the nurses' perspective, EOL research in the emergency department has generally focused on 3 primary aspects: issues regarding the nurse's workload while caring for dying patients, care of family members in addition to care of dying patients, and difficulties in providing quality EOL care in emergency departments with poor department design. 
The workload of nurses who are caring for dying patients has been reported in several studies. In 2 previous studies, randomly selected nurses who were ENA members reported that their assigned workloads were too high to provide quality EOL care. ${ }^{4,5}$ Additionally, nurses reported being pulled away from EOL care to assist with other patients and department obligations, resulting in disjointed care for the dying patient. ${ }^{2,6}$ To improve and provide optimal EOL care, nurses suggested increasing the amount of time available to spend with dying patients, recommending one-to-one nursing care for EOL patients. ${ }^{6}$

Care of family members of dying patients has been a second focus of previous studies. In a study of 236 nurses working in rural emergency departments, emergency nurses reported frequent calls from both family members and friends seeking patient condition updates as a major obstacle to providing EOL care. ${ }^{2}$ Additionally, as a liaison, nurses often intercepted distraught and angry family members, ${ }^{4}$ preventing nurses from spending valuable time with the dying patient. This lack of intermediary staff was especially evident in rural facilities where the presence of family support services such as social workers and religious leaders was limited. ${ }^{2}$

Regarding ED design, nurses from rural and urban emergency departments reported that ED designs did not allow for adequate privacy for dying patients and grieving family members. ${ }^{2,4}$ When asked how to improve EOL care, a national, random sample of 230 emergency nurses suggested greater privacy for patients and family, including provision of a separate family grief room. ${ }^{6}$ These nurses suggested a designated grief room that would allow family members to grieve privately, away from the noise and distraction of the busy emergency department.

Given the ever-increasing aged population and the rate of death that occurs in emergency departments nationally, it is imperative that both supportive behaviors and obstacles to providing EOL care in emergency departments be identified. Because research regarding EOL care in rural emergency departments is limited, the purpose of this study was to identify suggestions emergency nurses might have to improve EOL care in rural emergency departments. Therefore, the research question posed to rural emergency nurses for this study was, "If you had the ability to change just one aspect of the end-of-life care given to dying ED patients in a rural setting, what would it be?"

\section{Methods}

\section{STUDY DESIGN}

A cross-sectional survey research design was used for this study. Included in this design were 3 open-ended questions.

\section{INSTRUMENT}

The Rural Emergency Nurse's Perception of End-of-Life Care questionnaire was used to assess nurses' perceptions of the magnitude and frequency of a set of listed obstacles to providing EOL care in rural emergency departments. ${ }^{2}$ The questionnaire was modified from questionnaires used in previous ED EOL care studies and was then adapted to focus specifically on emergency care in rural settings. ${ }^{5}$ This 57-item questionnaire included 39 Likert-type items, 15 demographic questions, and 3 open-ended questions. The questionnaire was pretested by 15 nurses in 2 rural emergency departments in the Intermountain West. Feedback concerning content, questions, and completion time was obtained from the ED nurses. The amount of time required to complete the questionnaire was approximately 25 minutes. Findings for the quantitative data were published previously. ${ }^{2}$ Participants were also asked to answer 3 open-ended questions for qualitative purposes. This article reports findings from the open-ended questions.

\section{SETTING, SAMPLE, AND STUDY PROCEDURES}

Five states were selected to participate in the study based on the number of Critical Access Hospitals (CAHs) available in each of the states (see the Figure). ${ }^{7}$ CAHs are hospitals certified under a set of Medicare Conditions of Participation and located in rural areas of the United States. ${ }^{8}$ The 5 states selected were Utah, Idaho, Nevada, Wyoming, and Alaska.

Sample inclusion criteria included nurses who worked in a rural emergency department, could read English, and had cared for at least one dying patient in an ED setting. Responses to the qualitative questions were entered into a word database. Each qualitative response was individually reviewed by 4 different nurse experts and coded using content analysis. The coders included an experienced researcher, an advance practice nurse researcher, a qualitative researcher, and a graduate student with 5 years of ED experience. After individual review, responses were divided into major and minor themes based on the number of items included in that theme.

After Institutional Review Board approval was obtained, ED managers in $73 \mathrm{CAHs}$ in the 5 states were contacted by phone. Phone messages were left for managers who were unavailable at the time of contact. Contact was attempted as many as 4 times. Managers who agreed to participate in the study were mailed study packets to be distributed among emergency nurses. Each packet contained a cover letter, a questionnaire, a self-addressed stamped return envelope, and a $\$ 1$ bill as compensation for completing the questionnaire. The packets were distributed to nursing 


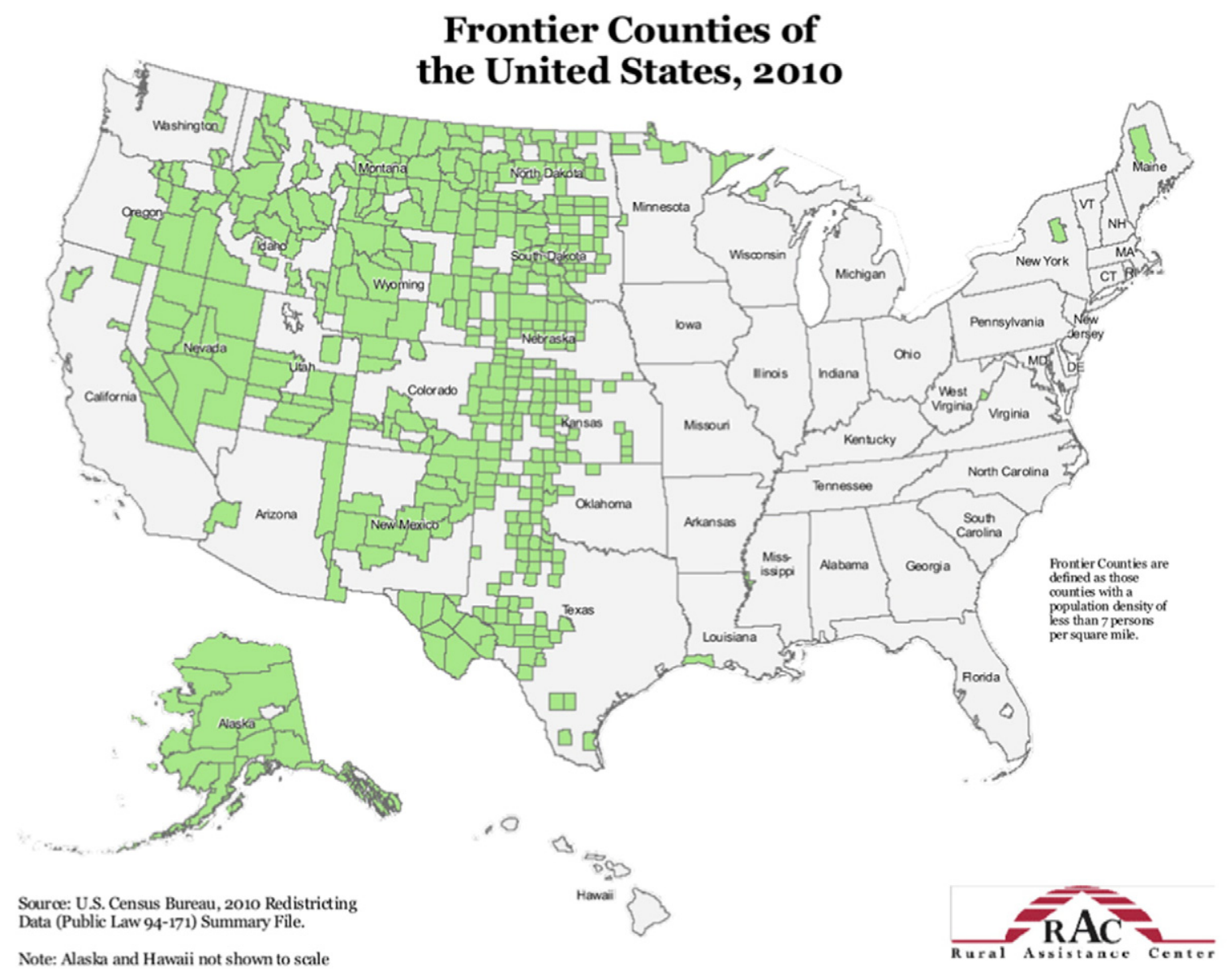

FIGURE 1

Frontier countries of the United States, 2010.

staff for completion. Nurses were not obligated to participate or complete the questionnaire. Consent to participate was assumed upon return of the questionnaire.

\section{Results}

Of the 73 CAHs contacted, 56 ED managers returned our calls of inquiry. Of those 56 managers, 53 (94.6\%) consented to distribute the questionnaire packets to ED nurses. Of the 508 questionnaire packets mailed to managers for distribution, 236 (46.4\%) were returned. Of those returned, 132 rural emergency nurses responded to the specified item asking respondents to identify one aspect of end-of-life care given to dying ED patients in a rural setting they would change if they had the ability to do so. Although nurses were asked to report just one aspect of EOL care they would like to change, 29 nurses provided multiple suggestions.
Of the 132 nurses who provided suggestions for improving EOL care in the emergency department, 117 $(88.6 \%)$ were female and $15(11.4 \%)$ were male. The mean age of participating nurses was $47(\mathrm{SD}=10.2)$ years. The mean years of registered nurse $(\mathrm{RN})$ experience in this sample was 15 $(S D=11.3)$, with a mean of $11.5(S D=10.2)$ years of $E D$ experience. Other demographic data are shown in the Table.

\section{MAJOR THEMES}

After reviewing rural emergency nurses' individual suggestions to improve EOL care, major and minor themes were identified. After analyzing all data, a natural gap was noted in the frequency of suggestions. Themes with 23 or more suggestions were identified as major while themes with less than 8 suggestions were considered minor. The major themes were ${ }^{1}$ : providing greater privacy during EOL care for patients and family members ${ }^{2}$; increasing availability of 
TABLE

\section{Study participants' demographic information}

\begin{tabular}{lcc} 
& Mean (SD) & Range \\
\hline Age, y & $47(10.2)$ & $25-67$ \\
Years as RN & $15.0(11.3)$ & $0-41$ \\
Years in emergency department & $11.5(10.0)$ & $<1-41$ \\
Years in rural nursing & $11.0(10.1)$ & $<1-41$ \\
Hours worked & $32.0(12.4)$ & $0-80$ \\
Years as CEN & $58(6.2)$ & $0-20$
\end{tabular}

Gender

Male

Female

Highest degree

Diploma

Associate

Bachelor

Master

Other

No. of dying patients cared for

$>30$

21-30

No response

Practice area

Direct care/bedside

$C E N$, Certified emergency nurse; $R N$, registered nurse; $S D$, standard deviation.

support services ${ }^{3}$; additional staffing; and ${ }^{4}$ improved staff and community education.

\section{Providing Greater Privacy During EOL Care}

Emergency nurses overwhelmingly $(\mathrm{n}=52)$ identified privacy as the top priority when providing EOL care in the emergency department. One nurse described the current situation with regard to privacy in the emergency department, stating, "Privacy in the ED does not exist. This needs to be changed." Three other nurses echoed this sentiment by suggesting the following: "privacy," "more privacy," and "better privacy."

Emergency nurses' suggestions for improved privacy was not limited to patients alone, but included greater privacy for family of patients as well. One nurse simply stated, "More privacy, especially for the family." Several nurses identified the need for a separate family consultation room or specified area dedicated for use of family members. One nurse suggested, "I wish we had a separate family meeting room for the family to wait in and have the doctor meet with them. We only have an ER waiting room." Another nurse recommended "having a separate area for families to gather and receive information away from public areas."

In addition to providing a separate family room, rural emergency nurses suggested changes in department design to ensure privacy and improve EOL care. One nurse stated, "I think if we had a private room designed and designated specifically for EOL patients, that would be ideal." Similarly, several nurses recommended designing single occupancy rooms to preserve privacy, especially in a rural setting. One 
nurse requested, "[a] better ED for privacy issues, separate rooms, not just pull curtains. This creates a lot of issues in a small town. Hearsay, rumors, etc." Another respondent agreed, saying, "Get a new hospital so the ED (sic) can have private rooms instead of curtains to separate the beds. The other patients don't have to listen to what is going on or making them wait in the lobby until end of life care is done."

\section{Increasing Availability of Support Services}

Many emergency nurses $(n=32)$ expressed the need for support services to provide quality EOL care to dying patients and their family members. One nurse suggested, "More readily available family support, whether from social work, chaplains, or just another nurse to be able to focus on the family needs." Similarly, another nurse suggested, "[the presence of a] social worker. [Support staff] help the family and friends so much to deal with the loss." Desperation was evident as one respondent requested, "More (any?) support staff-i.e., clergy; social worker; etc." Interestingly, another nurse identified a possible limitation that prevents the presence of support services in rural facilities, stating, "Rural hospitals being able to afford to pay for social workers."

\section{Additional Staffing}

Nurses also reported that staffing ratios decreased their ability to provide optimal EOL care in the emergency department $(n=26)$. One nurse said, "I would like to be able to devote more time to my dying patient and their family. Unfortunately, staffing does not allow for this all the time." Another nurse indicated, "Staffing is a skeleton crew. Quality time is a premium if the RN or LPN are free to give one-on-one care. [This] doesn't always happen. It would be nice to give all the time to the EOL patient."

Nurses also expressed the desire to be able to provide one-on-one care at the EOL and be relieved of other patient assignments and department duties. One nurse wished, “... that staffing would allow for one nurse, experienced in EOL care, to provide uninterrupted complete nursing care to the patient and family members throughout the patient's stay in the ER." Another nurse suggested:

I would think that if we could get a nurse assigned to take care of just that particular patient instead of being assigned to several different patients and have several duties get done, the nurse assigned to just that one EOL patient could spend the quality time with the patient and family that is much need[ed] at that point in time.

\section{Education-Staff and Community}

Providing education to staff and to the rural community members was the fourth most recommended theme to improve EOL care in the emergency department $(\mathrm{n}=23)$. A participating nurse stated, "ER training does not really prepare you for end-of-life care." To improve EOL care, a nurse suggested receiving "more training on how to communicate with families who have lost or are losing loved ones." Another experienced nurse recommended "Some form of training on how to deal with dying patients that are either friends or family. In a rural setting, there is a high probability that the patient will be known to you.... As we keep getting newer, younger nurses, few of them have the life experience that teach them how to keep "performing" when faced with this [situation]."

Nurses also emphasized the importance of education for the community, including patients and family members. A nurse expressed, "I wish families had some way to gain knowledge on DNR, CPR, etc, so they would know informed choices at the end of their loved one's life. It is really hard to have a patient dying of cancer and the family wants CPR and everything done." Another nurse recommended "More education so that patient and family members have a realistic idea or understanding about the fact that the patient is going to die regardless of what we do. People need help getting past the denial stage and on to the acceptance stage."

\section{MINOR THEMES}

Three minor themes were also identified to improve EOL care in the rural emergency department. The minor themes had 8 or fewer respondents. The 3 minor themes included futility, pain control, and knowing the patient personally.

\section{Futility}

Inflicting unnecessary pain by performing ineffective or futile procedures were behaviors that nurses identified as detrimental during EOL care. A nurse recommended that "we should let more people die with dignity instead of torturing them with multiple procedures that will not improve quality of life." One nurse expressed a desire to put "less focus on 'SAVE HIM' and more focus on being at [the] bedside and supporting [the] patient and family." Another nurse wrote, "I would change treating EOL patients with anything but making them comfortable. When a 99-year-old patient is asking to die and nothing [can] be done, I wish family members could just let them go."

\section{Pain Control}

Managing and controlling pain during EOL care was a focus for several ED nurses $(n=5)$. When asked, "What one aspect of EOL care would you change?" a nurse said, "for 
the patient to be pain free." Another nurse expressed concern that pain medications were sometimes withheld to ensure the patient remained hemodynamically stable despite being at the EOL, stating, "Often we will withhold pain meds and anxiety meds because $\mathrm{B} / \mathrm{P}$ is low." To prevent unnecessary pain, one respondent desired to "have a specific end of life, comfort-measure-only policy in force."

\section{Knowing the Patient Personally}

Several emergency nurses $(n=4)$ emphasized the challenges and difficulties in providing EOL care to patients they know personally. Working in a rural community presents a unique challenge; as one nurse describes, "With our community being small, most people know each other, which is more often a problem at that time rather than a benefit." Another nurse articulated her desire, stating, "That we wouldn't know the patient personally." Similarly, another respondent describes the following challenge: "Family will be looking to you as their friend, to be constantly available for them while somehow trying to care for the patient at the same time. This is compounded when the patient is your own family and because of staffing, you are the only nurse in the ER."

\section{MISCELLANEOUS RESPONSES}

Aside from the major and minor themes, 10 responses were categorized as miscellaneous suggestions. Several of the items were associated with the family-for example, providing the family with a patient memento, more family involvement, and developing family care protocols. Additional suggestions included providing follow-up and feedback when patients are transferred, not knowing the patient's wishes, providing community hospice services, and overcoming language and cultural barriers. Three responses from the study could not be coded into a specific theme because a suggestion for improvement was not provided, and thus they were eliminated.

\section{Discussion}

The need to provide privacy to dying patients and grieving family members during EOL care is consistent with previously published data that indicates privacy is a priority when providing EOL care in the emergency department. ${ }^{6}$ Lack of privacy for dying patients and grieving family members related to poor department design was found to be the second ${ }^{5}$ and third ${ }^{4}$ greatest obstacles in providing EOL care in the emergency department in previous studies. Similarly, based on the published quantitative results of this study, rural emergency nurses also identified poor design as the third most significant barrier to providing EOL care in the emergency department. ${ }^{2}$ It is evident that poor department design is a barrier in preserving privacy during EOL care. This obstacle is especially burdensome in rural departments, which commonly lack the accommodations necessary to ensure privacy during death and grieving because of space and design constraints.

The lack of available support services in rural emergency departments is a major barrier to providing quality EOL care to patients and family members. However, lack of support services appears to be a unique obstacle that affects rural emergency departments. ${ }^{2}$ In a previously published qualitative study, lack of support services was identified as only a minor theme affecting EOL care. ${ }^{6}$ Similarly, limited availability of support personnel also ranked low in 2 other ED studies that surveyed nurses nationwide. ${ }^{4,5}$ Nevertheless, the availability of support services greatly reduces the responsibility emergency nurses are expected to assume during EOL care. As social workers or chaplains assume part of the workload, nurses are able to focus their attention on the patient, thus maximizing the quality of care given to the patient. It is likely that rural emergency nurses identified this barrier as larger compared with nurses in other emergency departments because the number of resources available in rural hospitals tends to be more limited when compared with urban settings.

Emergency nurses' responses regarding staffing necessitate reconsideration of current staffing practices in rural emergency departments. The ENA position statement regarding staffing and productivity indicates that staffing should be assessed routinely to assure safe and efficient care. ${ }^{9}$ Similar to the results of this study, staffing limitations were identified as a major obstacle in providing EOL care in 2 previous ED-focused studies. ${ }^{5,6}$ These similarities confirm the necessity of re-evaluating staffing practices and ensuring that nurses are assigned manageable workloads.

\section{Limitations}

A limitation of this study is that it was a convenience sample of nurses rather than a random sample because of our need to obtain rural emergency nurses from CAHs. Although the sample was not randomized, the response rate was high at $47 \%$. This study was also limited geographically to the U.S. Intermountain West region, as well as to CAHs. Therefore, these results are not representative of other regions or non-CAH hospitals.

A second limitation was that not all CAH emergency departments in the chosen states were able to be contacted. 
Rural emergency nurses who were in these hospitals may have provided different suggestions for improving EOL care.

\section{Implications for Rural Emergency Nurses}

Rural emergency nurses' suggestions for EOL care improvement have commonalities across state lines. Administrators of rural hospitals should consider these nurses' suggestions for improved privacy as they plan upgrades for emergency departments or design new emergency departments. Department managers and nurse educators should seek to include EOL education routinely in staff meetings and updates. If funds for additional skilled help are prohibited by budget realities, managers also may consider opening more volunteer community positions for their rural emergency departments as a means to increase help for nurses, even if the help is not specifically skilled in health care delivery. Future research on EOL care obstacles is needed.

\section{Conclusion}

Patient deaths are a common occurrence in emergency departments nationwide, and providing care to dying patients is a demanding task that requires significant resources. Providing EOL care is especially difficult in rural settings, where resources and staffing are limited. However, by identifying and implementing supportive behaviors and acknowledging the obstacles that rural ED nurses encounter during EOL care, changes can be made to improve the treatment they provide to patients and family members during this trying time. Because of the current lack of research in rural ED settings, additional research is justified in the area of rural EOL nursing care.

\section{REFERENCES}

1. Centers for Disease Control and Prevention. National hospital ambulatory medical care survey: 2010 emergency department summary tables. http://www.cdc.gov/nchs/data/ahcd/nhamcs_emergency/ 2010_ed_web_tables.pdf. Accessed October 30, 2015.

2. Beckstrand RL, Giles VC, Luthy KE, Callister LC, Heaston S. The last frontier: rural emergency nurses' perceptions of end-of-life care obstacles. J Emerg Nurs. 2012;38(5):e15-e25.

3. Albert M, McCaig LF, Ashman JJ. Emergency department visits by persons aged 65 and over: United States, 2009-2010 (report No. 13). Hyattsville, MD: National Center for Health Statistics; 2013.

4. Heaston S, Beckstrand RL, Bond AE, Palmer SP. Emergency nurses' perceptions of obstacles and supportive behaviors in end-of-life care. $J$ Emerg Nurs. 2006;32(6):477-485.

5. Beckstrand RL, Smith MD, Heaston S, Bond AE. Emergency nurses' perceptions of size, frequency, and magnitude of obstacles and supportive behaviors in end-of-life care. J Emerg Nurs. 2008;34(4):290-300.

6. Beckstrand RL, Wood RD, Callister LC, Luthy KE, Heaston S. Emergency nurses' suggestions for improving end-of-life care obstacles. J Emerg Nurs. 2008;38(5):e7-e14.

7. U.S. Department of Health and Human Services, Rural Assistance Center. Frontier counties of the United States, 2010. http://www. raconline.org/racmaps/mapfiles/frontier.png. Accessed October 30, 2015.

8. U.S. Department of Health and Human Services, Health Resources and Services Administration. What are critical access hospitals (CAH)? http:// www.hrsa.gov/healthit/toolbox/RuralHealthITtoolbox/Introduction/ critical.html. Accessed October 30, 2015.

9. Emergency Nurses Association. Staffing and productivity in the emergency department. https://www.ena.org/SiteCollectionDocuments/ Position\%20Statements/Archived/StaffingandProductivity.pdf. Published 2011. Accessed October 30, 2015. 